\title{
Research on Ultrasonic Machining Gap Control Based on Fuzzy Self-tuning PID Parameters Technology
}

\author{
Chen Chun-hui ${ }^{1}$, Chen Wei-you ${ }^{2}$ \\ ${ }^{1}$ Naval Petty Officer Academy, Mechanical Department, lecturer, China \\ ${ }^{2}$ Naval Petty Officer Academy, Foundation, associate professor, China
}

\begin{abstract}
The working principle and measurement of ultrasonic machining gap is analyzed in this paper. A stable machining gap between the tool and workpiece must be maintained for improving processing accuracy and efficiency. Therefore, a fuzzy self-tuning PID parameters controller for ultrasonic machining tool feed system is designed, by means of using Matlab /Simulink simulation experiment, in this paper.
\end{abstract}

\section{Formulation of issues}

Onf the major concerns in any kinds of processing method is the producing proficiency. Ultrasonic machining is a method which process material by suspension abrasive material under the condition of a high-frequency vibration of the tool, thus, it is one of the most effective methods in processing hard and brittle materials such as glass and ceramics. Tool vibration amplitude and frequency, machining gap (that is, workpiece feed pressure produced by the tool) between the tool and the workpiece, abrasive suspensions, materials of the tool are the main factors that affect the processing speed. With other conditions remain unchanged, when the machining gap is too big, the impact of machining abrasive on the workpiece will decrease, resulting in decreased processing speed and reduced efficiency; when machining gap is too small, machining abrasive will be squeezed out, reducing the amount of abrasives, also resulting in decreased processing speed and reduced efficiency. To ensure accuracy and efficiency, we must maintain a stable machining gap (usually slightly larger than the average diameter of abrasive) between the tool and the workpiece. Therefore, under certain conditions, the controlling ultrasonic machining gap is a critical issue to improve ultrasonic machining productivity. In this paper, we mainly discuss the ultrasonic machining gap control based on fuzzy self-tuning PID parameter technology.

\section{Basic principle of ultrasonic machining}

Ultrasonic machining is a forming processing method in which the end face of an ultrasonic machine tool (Fig:1) is made ultrasonic vibration, by use of abrasive suspension to process brittle materials. Ultrasonic generator produces more than $16000 \mathrm{~Hz}$ high frequency
AC power supplied to the ultrasonic transducer to generate ultrasonic

Vibrations, and the amplitude is amplified up to about $0.05 \sim 0.1 \mathrm{~mm}$ by means of the horn, so that the lower end of the tool horn generates strong vibration. The suspension, containing water and an abrasive material, driven by the

Tool, also produces a strong vibration, impacting the surface of the workpiece. When machining, the tool puts a tiny pressure on the workpiece and the abrasive surface, continuously impacted by abrasive material with great speed and accelerated velocity, is crushed into small particles, falling down from the surface. The tool continuous feeds and the processing goes on until finally the desired size is reached and the shape of the tool is "Copied" on the workpiece.

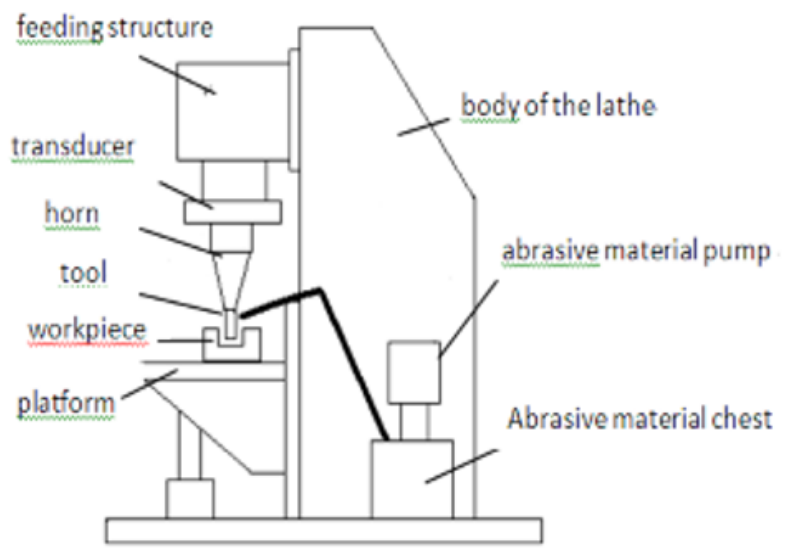

Fig. 1. Structure of Ultrasonic Machine Tool

\section{Measure and control principle of machining gap}


Ultrasonic resonance principle can be used to measure the gap between the tool and the work piece. Figure 2 is an ultrasonic machining gap measure and control system illustrative diagram. When machining, the ultrasonic is transformed into mechanical oscillation by machining transducer, then amplified by the horn and passed to tools.In order to improve the processing precision and efficiency,we expect the gap between tool and workpiece to be maintained at the set valuee $=\lambda / 2(\lambda$ is ultrasonic propagation wavelength measured in the abrasive suspension). When measured, pulse excitation transducer converts signal into measured ultrasound and launched and spread to abrasive suspension by the horn.Part of the ultrasonic waves are reflected at the interface, others pass through the suspension and reach the surface of the work piece, resulting in reflection and transmission. When the gap between the workpiece and the tool is $\lambda / 2$, or $n \lambda / 2$ ( $n$ is an integer), the ultrasonic waves and its reflected waves transmitback and forthin the suspension and interfere with each other precisely in the same phase.According to the principle of resonance, as the ultrasound energy transmitted from the horn to abrasive suspension is reduced, ultrasonic amplitude is reduced accordingly. Based on the circuit feedback signal, CNC system then decideswhether the gap between the workpiece and the tool is equal to $\lambda / 2$ or $n \lambda / 2$.If it is equal to $\lambda / 2$ or $n \lambda / 2$, the gap information will be sent back to CNC system;if it is not equal to $\lambda / 2$ or $n \lambda / 2$, the feed structure will keep feeding until the machining gap is equal to $\lambda / 2$ or $n \lambda / 2$.

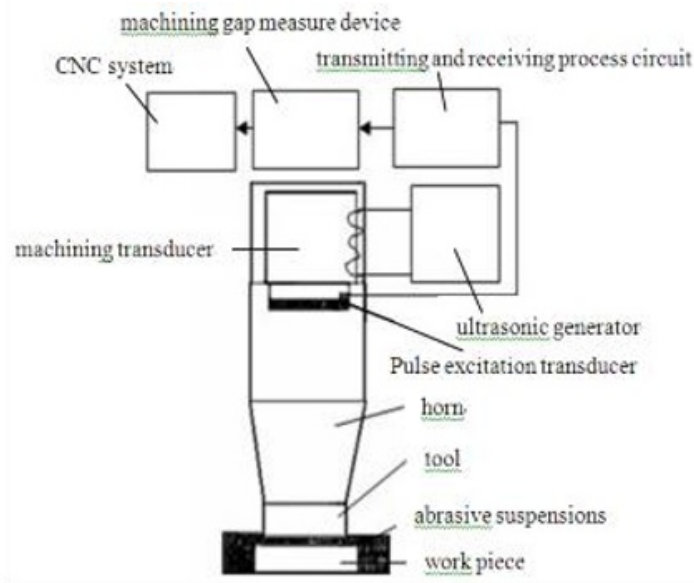

Fig. 2. Ultrasonic Machining Gap Measure and Control System

\section{Design of fuzzy self-tuning PID parameters controller}

\subsection{Design}

Conventional PID control is simple in principle and easy to use, but its control methods are mostly to be fixed a set of adjustable parameters under certain performance requirements. Such controls cannot often give attention to both static and dynamic performance, therefore the control of the system is not optimal. As to the fuzzy control, in which the mathematical model of the controlled objectis not necessarily to be known, it is easy to implement the control on uncertain or nonlinear systems and has a strong robustness to the parameters of the controlled objects, also it has strong suppression to external interference, and other similar characters. We, in this paper, try to combine the advantages of PID fuzzy control and design the fuzzy self-tuning PID parameters controller, with the function of identifying fuzzy relations between the three parameters, scale factor, integration constant and differential constant, and the error as well as error rate of change. It also keeps detecting error and error rate of change, and then revises the three parameters according to the fuzzy control principle, to meet the requirements of errors and error rate of change to the three parameters, thus the control system processes good dynamic and static performance.

\subsection{Structure}

The fuzzy self-tuning PID parameters controller consists of PID controller in which the parameters are adjustable and fuzzy controller. The fuzzy controller takes the deviation $\mathrm{e}$ and deviation rate of change ec of the ultrasonic machining gap as input value, the three parameters $\mathrm{K}_{\mathrm{p}}, \mathrm{K}_{\mathrm{i}}, \mathrm{K}_{\mathrm{d}}$ of the conventional controller as output value, and then conducts real-time adjustments to $\mathrm{K}_{\mathrm{p}}, \mathrm{K}_{\mathrm{i}}, \mathrm{K}_{\mathrm{d}}$ with fuzzy inference methods so as to meet the requirements of deviation $\mathrm{e}$ and deviation rate of change to PID parameters in different time.The structure of the composition of the controller is shown in Fig.3.

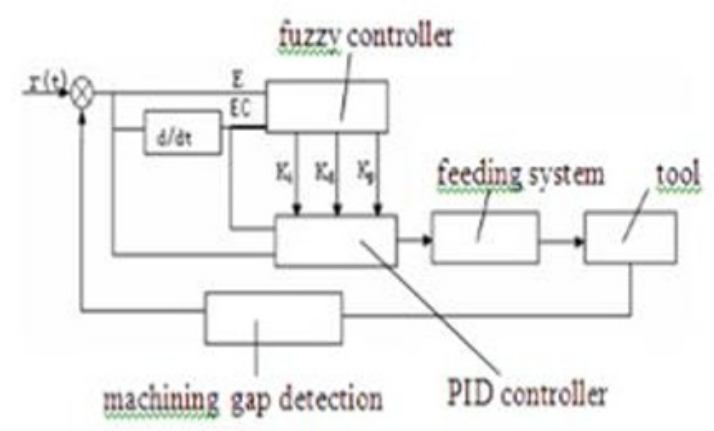

Fig. 3. Structure of Fuzzy Self-Turning PID Parameters Controller

\subsection{Design of fuzzy control}

The design of fuzzy control system employs two inputs (E, EC), triple-outputs $\left(\triangle K_{p}, \triangle K_{i}, \triangle K_{d}\right)$. The fuzzy domain of error e and error change rate ec is: $\mathrm{E}, \mathrm{EC}=\{-6$, $-5,-4,-3,-2,-1,0,1,2,3,4,5,6\}$.The language variable value is taken as $\mathrm{E}, \mathrm{EC}=\{\mathrm{NB}, \mathrm{NM}, \mathrm{NS}, \mathrm{ZE}, \mathrm{PS}, \mathrm{PM}$, PB $\}$. The fuzzy domain of $\triangle K_{p}, \triangle K_{i}, \triangle K_{d}$ of is: $\triangle K_{p}$,

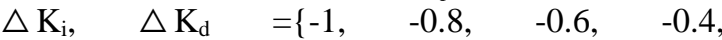
$0.2,0,0.2,0.4,0.6,0.8,1\}$, and the language variable value is taken as $\triangle K_{p}, \triangle K_{i}, \triangle K_{d}=\{N B, N M, N S, Z E$, PS, PM, $\mathrm{PB}\}$. The membership functions of input and output variables are taken evenly distributed triangular 
membership function. The membership function distribution curve of E, EC is shown in Figure 4 andthe membership function profiles of $\triangle K_{p}, \Delta K_{i}, \Delta K_{d}$ is shown in Figure 5.The control rules of parameters $\triangle K_{p}$, $\triangle \mathrm{K}_{\mathrm{i}}, \triangle \mathrm{K}_{\mathrm{d}}$ are shown in Table 1, Table 2 and Table 3.The control rules of fuzzy PID parameter self-tuning controller is shown in Figure 6.

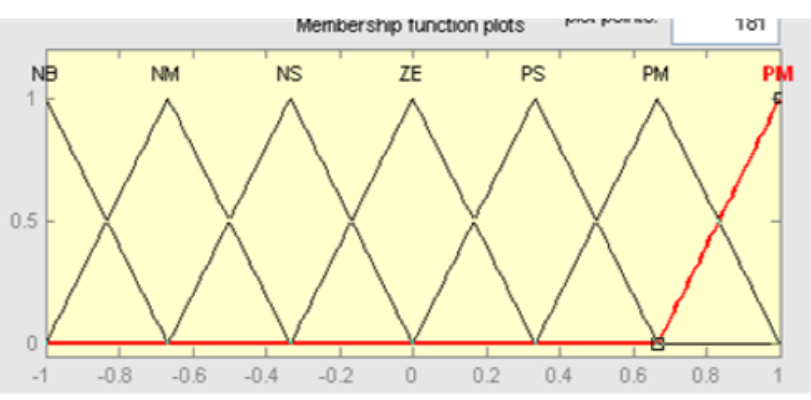

Fig. 4. Membership Function Distribution Curve Of E, EC

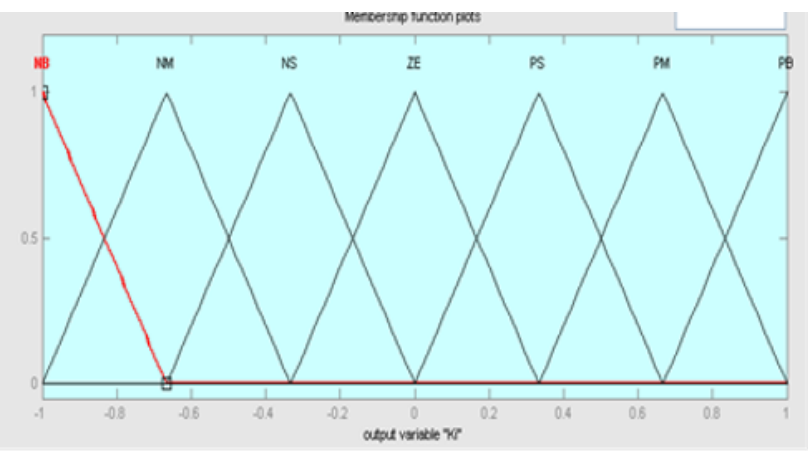

Fig. 5. Membership Function Profiles Of $\triangle K p, \triangle K i, \triangle K d$

Table 1. Control Rules of Parameters $\triangle \mathrm{Kp}$

\begin{tabular}{|l|l|l|l|l|l|l|l|}
\hline FB & NB & NM & NS & ZE & PS & PM & PB \\
\hline NM & PB & PB & PM & PS & NM & ZE & ZE \\
\hline NS & PB & PM & ZE & ZE & ZE & ZE & PS \\
\hline ZE & PB & PM & ZE & ZE & ZE & PS & PB \\
\hline PS & PB & PS & ZE & ZE & ZE & PS & PB \\
\hline PM & PS & PS & NS & NS & PS & PM & PB \\
\hline PB & ZE & ZE & NM & NS & PM & PM & PB \\
\hline
\end{tabular}

Table 2. Control Rules of Parameters $\triangle \mathrm{Ki}$

\begin{tabular}{|l|l|l|l|l|l|l|l|}
\hline NB & NB & NM & NS & ZE & PS & PM & PB \\
\hline NM & PB & PB & PM & NM & NM & ZE & ZE \\
\hline NS & PB & PM & PS & NS & ZE & PS & PS \\
\hline ZE & PB & PM & PS & ZE & PS & PM & PB \\
\hline PS & PB & PS & ZE & NS & PS & PB & PB \\
\hline PM & PS & PS & NS & NS & PM & PB & PB \\
\hline PB & ZE & ZE & NM & NM & PB & PB & PB \\
\hline
\end{tabular}

Table 3. Control Rules Of Parameters $\triangle \mathrm{Kd}$

\begin{tabular}{|c|l|l|l|l|l|l|l|}
\hline $\mathrm{EE}$ & NB & NM & NS & ZE & PS & PM & PB \\
\hline $\mathrm{NB}$ & PB & PM & PB & PB & PB & ZE & NB \\
\hline
\end{tabular}

\begin{tabular}{|l|l|l|l|l|l|l|l|}
\hline NM & PB & PS & PM & PM & PM & NS & NB \\
\hline NS & PM & PS & PS & PS & PS & NB & NB \\
\hline ZE & ZE & ZE & ZE & ZE & ZE & ZE & ZE \\
\hline PS & NB & NM & PS & PS & PS & PS & PS \\
\hline PM & NB & NS & PM & PM & PM & PS & PM \\
\hline PB & NB & ZE & PB & PB & PB & PM & PB \\
\hline
\end{tabular}

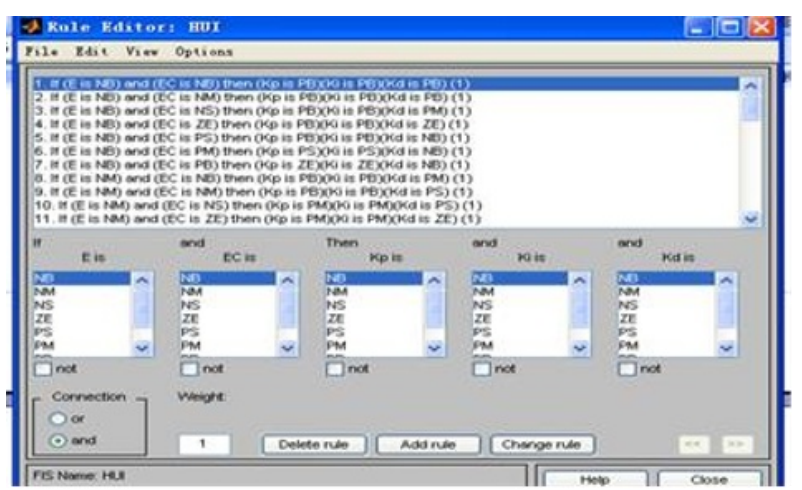

Fig. 6. Control Rules of Fuzzy PID Controller

\section{Simulation experiment based on simulink simulation}

In order to verify the control effect of fuzzy self-tuning PID parameters controller, and for comparison, we apply the software Mtlab/Simulink to conduct the simulation experiment and analysis on conventional PID control and fuzzy self-tuning PID control. The common second order delay in actual control tasks is selected as the control object. Suppose the transfer function is:

$$
G(s)=\frac{20 \quad e^{-2 s}}{S^{2}+3 S+5}
$$

\subsection{Conventional PID control system simulation experiment}

Conventional PID control system simulation model shown in Figure 7.

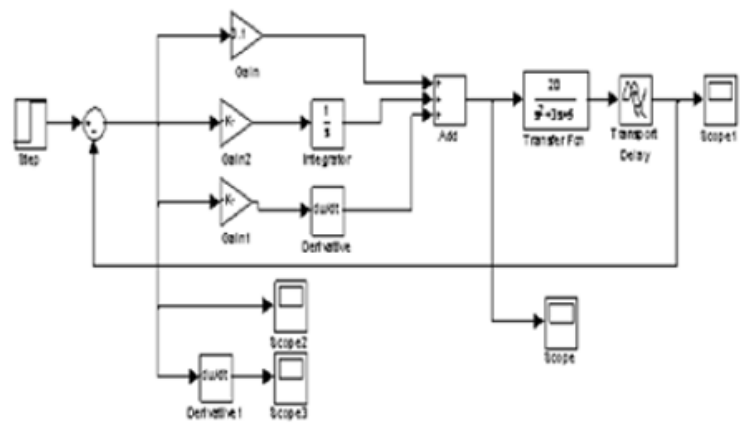

Fig. 7. Conventional PID Control System Simulation Model 
In the role of unit step signal, we take sampling time $\mathrm{T}=0.1$ seconds, the simulation time $\mathrm{t}=60$ second, PID controller parameters $\mathrm{K}_{\mathrm{p}}=0.1, \mathrm{~K}_{\mathrm{i}}=0.12, \mathrm{~K}_{\mathrm{d}}=0.01$, then we get the output waveform of the system shown in Figure 8, system deviation e and deviation change rate e care shown in Figure 9 and Figure 10, respectively, andthe curve of the PID controller output $u$ changes in pace with time $t$ is shown in Figure 11.

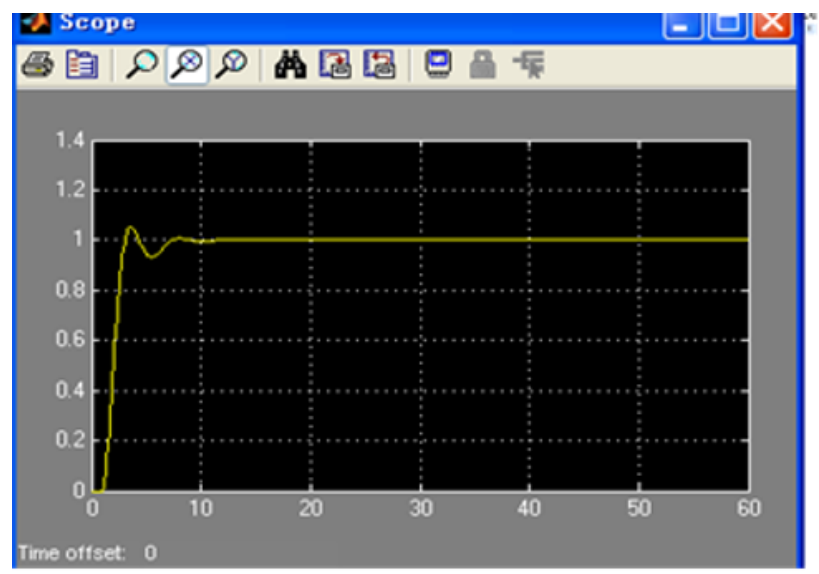

Fig. 8. Simulation Effect of Conventional Control System

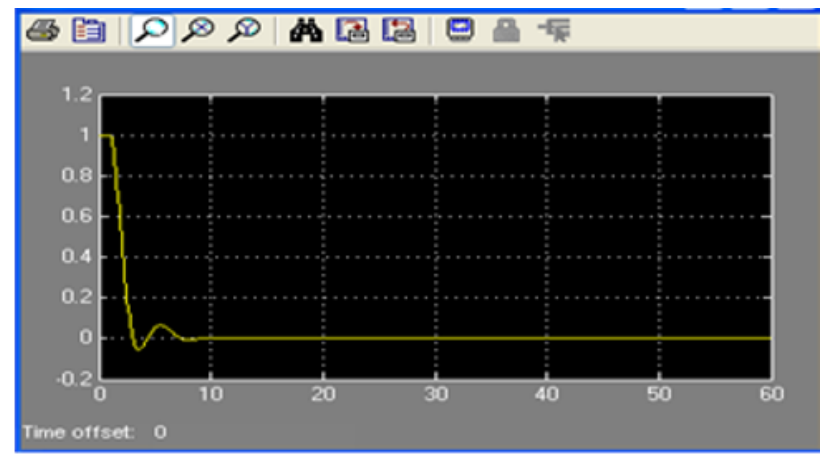

Fig. 9. Curve of Deviation E In Pace With Time T

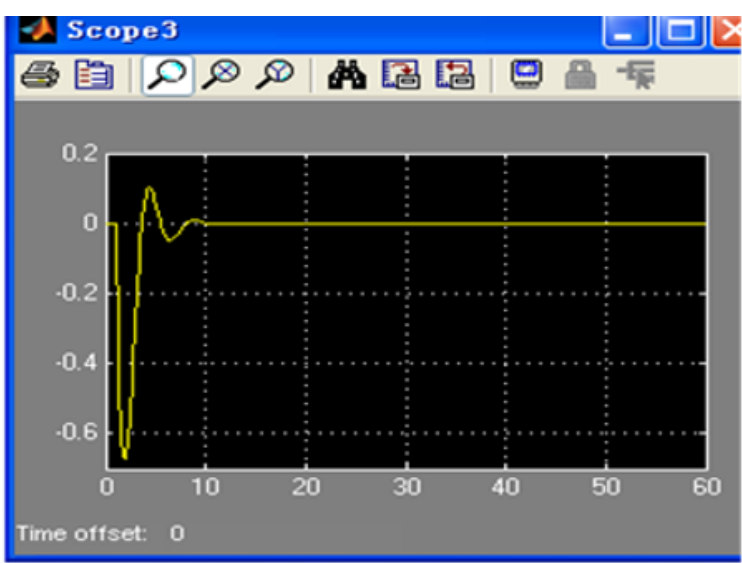

Fig. 10. Curve of Deviation Change Rate E in Pace with Time $\mathrm{T}$

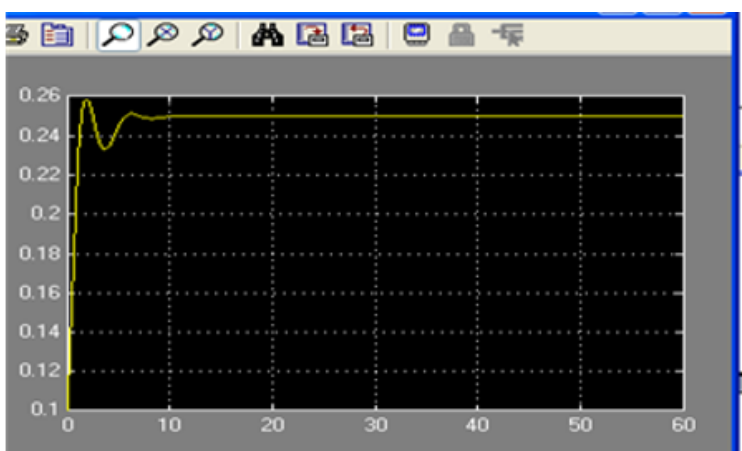

Fig. 11. Curve of PID Controller Output U in Pace with Time $\mathrm{T}$

\subsection{Fuzzy PID self-turning parameters controller simulation experiment}

Based on Figure 8, Figure 9, Figure 10, we decide the basic domain to be $\mathrm{e} \in(-0.2,1)$, ec $\in(-0.8,0.2)$, $\triangle \mathrm{K}_{\mathrm{p}} \in(0.22,0.26), \triangle \mathrm{K}_{\mathrm{i}} \in(0.22,0.26)$,

$\triangle \mathrm{K}_{\mathrm{d}} \in(0.22,0.26)$. In the role of the unit step signal through repeated experiments, we take quantitative factors to be $\mathrm{K}_{\mathrm{e}}=0.8, \mathrm{~K}_{\mathrm{ec}}=0.35$, scale factor $\mathrm{G}_{\mathrm{kp}}, \mathrm{G}_{\mathrm{ki}}, \mathrm{G}_{\mathrm{kd}}$ were $0.01,0.001,0.01$. Then fuzzy self-tuning PID parameters controller simulation model is shown in Figure 12. The simulation result of the system in the role of unit step signal is shown in Figure 13.

To compare the simulation results in Fingure 8 and Figure 13, we can see that the fuzzy PID parameter selftuning controller discussed in this article can be well used to control machining gap, to improve processing quality and efficiency, at same time free of such shortcomings as large overshoot amount and long time for adjustment that exist in conventional PID controlling.

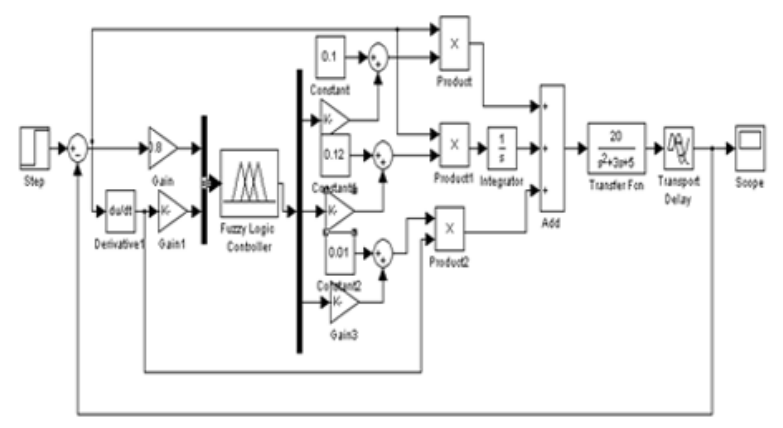

Fig. 12. Simulation Model of Fuzzy PID Parameter SeifTurning Control System 


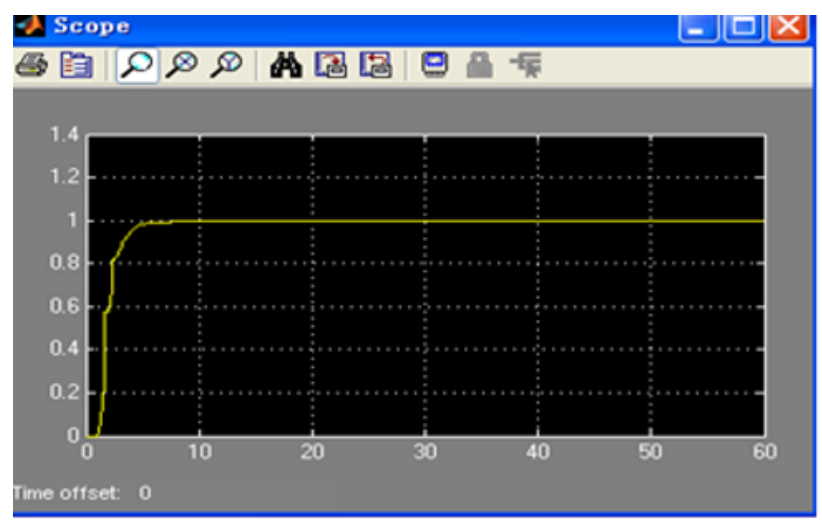

Fig. 13. Simulation Result in the Role of Unit Step Signal

\section{Conclusion}

Machining gap is a critical parameter in ultrasonic CNC machining. This article puts forward that fuzzy selftuning PID parameters controller is used to control the feed system of ultrasonic CNC machine tool to ensure a stable machining gap between the tool and the workpiece. Matlab/Simulink simulation software is applied to conduct the experiment on the designed system, and proved to have good results for it achieves an on-line control of the process.

\section{References}

1. Zhong Jin'an. Research on Ultrasonic Machining gap Online Measurement and control[J]. Chinese Journal of Instrument. 2002(6).vol.23.

2. Song Zhen. Simulation Research on the Establishment of ultrasonic vibration cutting system and horn performance. Master Proceedings of Harbin Institute of Technology[C]. 2006.6:1-12.

3. Luo Yue, Zhang Mingjun, Kong Jinxing. Design on Ultrasonic Vibration Turning Device. Teaching and Technology[J]. 2005(J).

4. Yang Yanglin, Yu Xingzhi, Zhang Chengguang. Application of Ultrasonic Machining Technology. Modern Machinery [J].2009.

5. Hu Chuanxin, Huang Yan, The Research of Fuzzy Control Method Based on Self-Adjusting Rules. Master Thesis of Shantou Uninversity[C]. 2003.

6. Feng Dongjv. A Simple Measurement of Tool Amplitude for Ultrasonic CNC machining. Electrical Processing and Model[J]. 2004(5).

7. Zhang Li, Li Zhong, Liu Yanquan. Expert Selftuning Fuzzy Control System. Chinese Journal of Scientific Instrument [J]. .2004(3):34-37.

8. Li Zhuxin. A Double Model Controller with Selfadjusting Base Sets Using Fussy Switching Based on Fussy Rules. Journal of Yunnan University[J]. 2003(4):313-316.

9. $\mathrm{Hu}$ Chuanxin. Special Processing Handbook[M]. Beijing University of Technology Press.2011.
10. Feng Dongqing, etc. Design of PID-Controller with Fuzzy Self-adjusting Parameter and Its Robustness Analysis. Proceedings of Progress of Computer Technology and Applicationin the 18th CACIS[C]. 2007.

11. FangGenSun, LongJingFan. N-widths on the classes of multivariate bandlimited unctions.Progressin Natural Science.2004,(10):863866.

12. D.M .Alter, etc. Control of Linear Motors for Machine Tool Feed DrivesDesign and Implementation of $\mathrm{H} \infty$ Optimal Feedback Control.Journal of Dynamic Systems.Measurement and control, 1996, (1):18.

13. T.H.Lee, etc.Intelligent Control of Precision Linear Actuators.E ngineering Applications of Artifical Inteligence.2000, (13):671-684

14. David M.Alter, etc.Control of Linear Motors for Machine Tool Feed Drives Experimental Investigation of Optimal Feed-forward Tracking Control.Journal of Dynamic System, Measurement and Control.1998, (3):221-225

15. Velthuis, etc.Experimental Verification of the Stability Analysis of Learning Feed-Forward Control.Proceedings of the IEEE Conference on Decision and control.1998, (2) : 1225-1229

16. Bassi, etc.Force Disturbance Compensation for An A.C.Brushless Linear Motor.IEEE International Symposium on Industrial Electronics.1999, (3) : 1350-1354

17. $\mathrm{Su} \mathrm{Li}$, etc.Adaptive Robust Precision Motion Control of Linear Motors with Negligible Electrical Dynamics Theory and Experiments.Proceeding of the A merican Control Conference.IEEE , Piscataway,NJ,USA,OOCB36334.2000,4: 25832587

18. Kim, etc. Robust Internal Loop Compensator Design for Motion Control of Precision Linear Motor. IEEE International Symposium on Industrial Electronics.1999,3: 1045-1050.

19. Layne J R, Passino K M. Fuzzy Model Reference Learning Control for a Cargo Ship Steering .IEEE Control Systems.1993:23-34

20. GCGoodwin, S F Graebe,M E Salgado.Control System Design.Prentice Hall,2001.

21. LennartLjung.System Identification Toolbox User's Guide.The MathWorks Inc, 2001.

22. Jean-JacquesE.Slotine.Applied Nonlinear Control.China Machine Press,2004.

23. WangLei,XiaoYun-shi,WuQi-di,ZhouGuo-

Xing.Neural nerwork based $p$ arameters identification and adaptive speed control of AC drive system.P roceedings of the IEEE International conference on industrialte chnology, 1996. 
24. D.Renton,etc. High Speed Servo Control Multiaxis Machine Tools. International Journal of Machine Tools\&Manufacture.2000, (40): 539-559.

25. M.Gringel, etc.Machine Tool Design Requirements for High-Speed $M$ achining.Annals of the CIRP.1996, (1):1-5.

26. Kim , etc.Robust Internal Loop Compensator Design for Motion Control of Precision Linear Motor.IEEE International Symposium on Industrial Electronics.1999,3: 1045 -1050.
27. Lin $\mathrm{C}$ T and Lu Y C .Aneural fuzzy system with fuzzy supervised learning.IE EE Trans.Syst., Man and Cybem.1996, (5):744-763.

28. Rajani K. Mudi and Nikhil R.Pal. A Robust SelfTuning Scheme for PI-and PD-Type Fuzzy Controllers.IEEE Trans.Fuzzy Syst.1999, (7):3-16. 